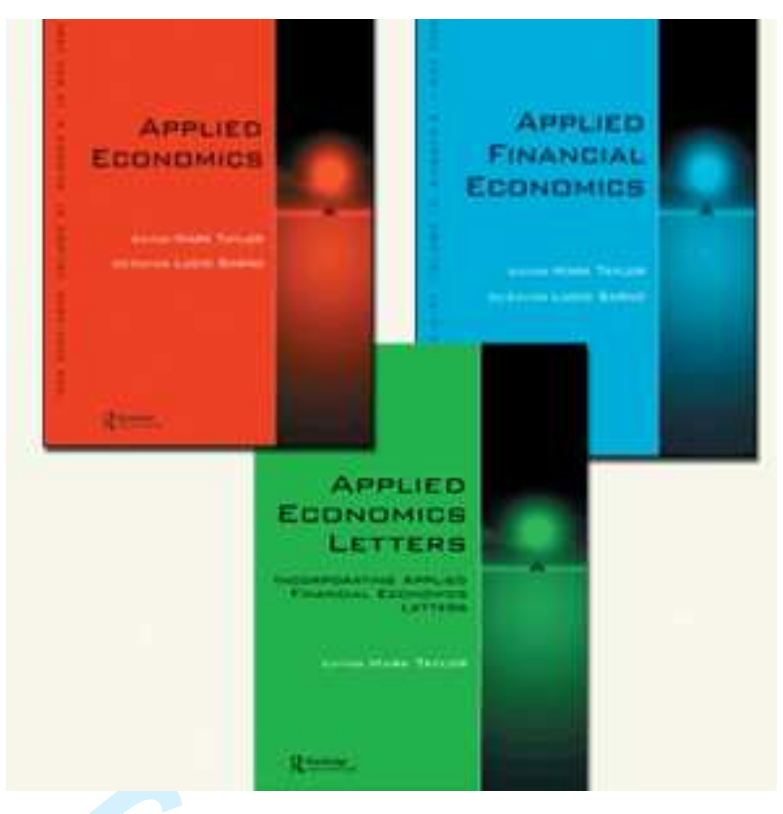

\title{
Analyses of Technical Efficiency Using SDF and DEA Models: Evidence from Nepalese Agriculture
}

\begin{tabular}{|c|c|}
\hline Journal: & Applied Economics \\
\hline Manuscript ID: & APE-2009-0498.R1 \\
\hline Journal Selection: & Applied Economics \\
\hline $\begin{array}{r}\text { Date Submitted by the } \\
\text { Author: }\end{array}$ & 02-Nov-2010 \\
\hline Complete List of Authors: & $\begin{array}{l}\text { Bjorndal, Trond; University of Portsmouth, CEMARE } \\
\text { Adhikari, Chandra; Tribhuvan University, Centre for Nepal and } \\
\text { Asian Studies (CNAS) }\end{array}$ \\
\hline JEL Code: & $\begin{array}{l}\text { D24 - Production |Capital and Total Factor Productivity |Capacity }< \\
\text { D2 - Production and Organizations < D - Microeconomics, L25 - } \\
\text { Firm Size and Performance }<\text { L2 - Firm Objectives, Organization, } \\
\text { and Behavior }<\text { L - Industrial Organization, Q12 - Micro Analysis of } \\
\text { Farm Firms, Farm Households, and Farm Input Markets }<\text { Q1 - } \\
\text { Agriculture }<\text { Q - Agricultural and Natural Resource Economics }\end{array}$ \\
\hline Keywords: & Technical efficiency, Farm size, DEA, Nepal \\
\hline
\end{tabular}




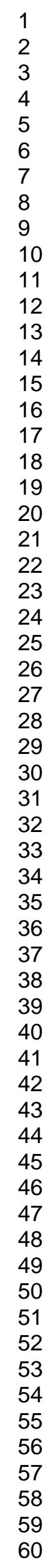

\section{SCHOLARONE ${ }^{m}$ \\ Manuscripts}

7

25

26

27

29

30

31

33

34

35

36

37

38

41

42

43

45

46

47

48

49

51

52

53

54

55

57

58

59

60 


\title{
Analyses of Technical Efficiency Using SDF and DEA Models: \\ Evidence from Nepalese Agriculture \\ by
}

\author{
Chandra Bahadur Adhikari \\ Centre for Nepal and Asian Studies (CNAS) \\ Tribhuvan University, Katmandu, Nepal \\ and \\ Trond Bjorndal ${ }^{1}$ \\ CEMARE \\ The University of Portsmouth
}

\begin{abstract}
Alleviation of poverty is a central issue in Nepal. Given the limited stock of land, and the infant/unorganised manufacturing sector, increased demand for food has to be satisfied by improving production efficiency. This paper examines how this could be achieved. SDF and DEA models identify the existence of a high degree of technical inefficiency in Nepalese agriculture, suggesting that there is a substantial prospect of increasing agricultural productivity using the existing level of inputs and resources more efficiently. Among the three farm sizes in the data set, medium size farmers achieve a higher technical efficiency than large and small farm sizes, suggesting that productive efficiency can be increased with the encouragement of creating medium size holdings. The observed decreasing returns to scale also implies that productivity gains could be achieved by breaking up of large farms into small family farms. The technical inefficiency model suggests the potential for shifting the production frontier upwards by providing ownership of land, increasing farmers' education and knowledge, and increasing land quality, including irrigation facilities.
\end{abstract}

JEL Classifications: D24; L25; Q12

Key Words: Technical efficiency; Farm size; Distance Function; DEA; Nepal

\footnotetext{
${ }^{1}$ Corresponding author. Corresponding address: CEMARE, University of Portsmouth, 141 High Street, Portsmouth, UK, PO1 2HY.. E-mail addresses: Trond.Bjorndal@port.ac.uk (T. Bjorndal).:chandra.adhikari@gmail.com (C. B. Adhikari)
} 


\section{Introduction}

In Nepal, much, time and effort have been employed in different sectors of the economy to reduce poverty and inequality. During the last decade, aggregate poverty declined, however, the decline was uneven across geographical regions. This resulted in a sharp increase in regional inequality. Recently, all political parties have agreed to alleviate poverty through land. However, as Nepal is a mountainous country, only a small part of the land can be brought under cultivation. Population pressure on the limited supply of useful land has been mounting over the years. Against this background, the aim of this article is to relate the principal findings from the empirical analyses of technical efficiency to the research questions viz whether land reform can be a viable strategy to alleviate poverty in a subsistence agricultural country like Nepal.

In this article two methods of analysis, namely the parametric stochastic distance function (SDF) and the non-parametric data envelopment analysis (DEA), will be applied using farm household survey data to measure technical efficiency in Nepalese agriculture. The primary analysis is based on the parametric SDF approach to measure levels of technical efficiency. Using the same data set, technical efficiency is also measured by applying the nonparametric DEA methodology to check the consistency and robustness of the specified model. The estimated technical efficiencies are also related across farm-size groups to address the age-old debate in the international literature on farm size and efficiency. The efficiencies will also be related to the specific geographic and ecological zones distinct to Nepalese agriculture.

The article is organised as follows. Section 2 briefly explains the basic characteristics of the farming system and the data. Moreover, the variables used to estimate the empirical models are defined. Section 3 presents the estimated results from the SDF frontier model. Technical efficiency scores are also connected to farm size and ecological zone. Section 4 estimates the non-parametric DEA model and compares the technical efficiency results with those derived from the parametric methodology. The article ends with conclusions and a discussion of policy implications in Section 5.

\section{Basic Characteristics of Farming, Data and Variables}

Nepal is a landlocked mountainous country. Steep slopes and permanent snow cover large areas; hence, only $20 \%$ of Nepal's total land is cultivated. Nepalese society is very hierarchical in nature in terms of production relations. Land appears to be one of the basic assets and the main source of income for the majority of Nepalese people. However, the scarce farmland is unequally distributed and typically misallocated among potential users (NPC, 1998; WB, 2006). Landowners, who have more agricultural land, have fewer farming skills, and those with more skills have less adequate land for cultivation. Cultivation methods are still non-mechanised. The landholding 
class that extracts the major share of the agricultural surplus largely invests in sectors other than agriculture. Agricultural productivity is much lower than in other countries in the region. Consequently, the relationship between land and poverty is embedded in Nepalese agrarian society.

The prospect of expanding agricultural land in Nepal is virtually non-existent. Increased food production to meet the needs of the growing population in the long term will have to come mainly through improvements in production efficiency and appropriate reorganisation of existing agricultural land. Hence, it is crucial to examine whether land reform can be a viable strategy in a subsistence agricultural country like Nepal. The answer to that question requires a comprehensive empirical study on productive efficiency in agriculture with respect to a redistributive land reform programme and its ability to ameliorate poverty.

The data for this study are taken from the Nepal Living Standards Survey (NLSS) conducted in 2003 by Central Bureau of Statistics (CBS) Nepal, following the World Bank's Living Standard Measurement Survey (LSMS) method. The survey provides a large database including detailed input and output data on agricultural production and a wide range of household-specific social and economic information. A final adjusted total sample of 2,585 households is used for the empirical analyses in this article. The NLSS (CBS, 2004) details sampling and data collection procedures as well as the instruments employed in the survey.

Agriculture is characterised by a joint production system where a specific set of inputs is commonly used to produce a specific set of outputs. Specifically, small farm households in Nepal engage in subsistence mixed farming. Cereal crops dominate the peasant households, who sell some surplus or purchase some deficit amount of food items. In this study four output variables viz., cereal crop $\left(q_{1}\right)$, pulses $\left(q_{2}\right)$, cash crops $\left(q_{3}\right)$ and other outputs $\left(q_{4}\right)$ are defined, incorporating 67 different crops, seven livestock products, and some other farm related production output contained in the survey data. Each output variable is measured in terms of Nepalese rupees (Rs) and is obtained by multiplying the physical quantity by its respective average price.

Six production variables are defined so as to encompass the inputs used in agricultural production. They are human labour $\left(\mathrm{X}_{1}\right)$, irrigated land $\left(\left(\mathrm{X}_{2}\right)\right.$, rainfed land $\left(X_{3}\right)$, capital stock $\left(X_{4}\right)$ purchased inputs $\left(X_{5}\right)$ and other costs $\left(X_{6}\right)$... In addition to the variables described above, eight relevant farm-specific variables are specified, including, owned land $\left(Z_{1}\right)$, value of land per hectare $\left(Z_{2}\right)$, extension Service dummy $\left(Z_{3}\right)$, age of the head of the household $\left(Z_{4}\right)$, family head's education $\left(Z_{5}\right)$ and access to road $\left(Z_{6}\right)$. As farming is carried out in three regions, mountain, hill and Terrai (plain), a mountain dummy $\left(Z_{7}\right)$ and a hill dummy $\left(Z_{8}\right)$ are also included in the inefficiency effect model.

In order to provide an insight into the age-old debate on small vs. large farm efficiency differences, following the World Bank (2006) this analysis aggregates groups of farms into three categories: small farms (less than 1.00 hectare), medium farms (1.00 hectare to 2.00 hectares), and large farms 
(2.00 hectares or more). Out of the total 2,585 farms in this study, 1,325 are small, 1,146 are medium and 114 farms are large farms. Descriptive statistics for the farm data are presented in Table 1.

\section{Parametric Stochastic Distance Function (SDF) Analysis}

The principal methodology employed to measure technical efficiency is the stochastic distance function (SDF) approach. The main reason for this specification is that agriculture in developing countries shows substantial variability in production due to random factors, including resource availability, missing variables, environmental influences, weather, and measurement errors. Consequently, the frontier and technical efficiency results derived from deterministic methodologies, as well as DEA methods, could lead to biased estimates because those methods do not address stochasticity in the empirical model. Agriculture is also a joint production system where multiple outputs are produced by using multiple inputs. Previous stochastic frontier analyses are based on a single output or aggregated single index output, implicitly assuming that the weight of all products is equal. To overcome this problem, the output distance function is specified to estimate the stochastic frontier that can accommodate the multi-output multi-input problem.

Most recent studies applying the distance function approach have made use of the translog form because imposing linear homogeneity in output is impossible for the other flexible functional forms (Pascoe, Koundouri and Bjørndal, 2007; Irz and Thirtle, 2005; Paul and Nehring, 2005; O'Donnell and Coelli, 2005; Coelli and Perelman, 1996, 2000). Following these studies, the distance function model in this study is specified by using a translog functional form.

The translog output distance function for $\mathrm{M}$ outputs and $\mathrm{P}$ inputs can be specified as:

$$
\begin{aligned}
& \ln D=a_{0}+\sum_{m=1}^{M} a_{m} \ln q_{m}+0.5 \sum_{m=1}^{M} \sum_{n=1}^{M} a_{m n} \ln q_{m} \ln q_{n}+\sum_{p=1}^{P} b_{p} \ln x_{p}+0.5 \\
& \sum_{p=1}^{P} \sum_{j=1}^{P} b_{p j} \ln x_{p} \ln x_{j}+\sum_{p=1}^{P} \sum_{m=1}^{M} g_{p m} \ln x_{p} \ln q_{m}
\end{aligned}
$$

where the $a_{o}, a_{m}, a_{m n}, b_{p}, b_{p j}$, and $g_{p m}$ are unknown parameters and In represents the natural logarithm. From Euler's theorem the homogeneity of degree one in outputs implies:

$$
\sum_{m=1}^{M} a_{m}+\sum_{m=1}^{M} \sum_{n=1}^{M} a_{m n} \ln q_{n}+\sum_{p=1}^{P} \sum_{m=1}^{M} g_{p m} \ln x_{p}=1,
$$

which will be satisfied if 


$$
\sum_{m=1}^{M} a_{m}=1, \sum_{m=1}^{M} a_{m n}=0 \text { for all } \mathrm{n}, \text { and } \sum_{m=1}^{M} g_{p m}=0 \text { for all } \mathrm{p}
$$

The symmetry restrictions require $a_{m n}=a_{n m}$ and $b_{p j}=b_{j p}$ for all $m, n, j$ and $p$. Following Lovell et al. (1994), we impose the homogeneity constraint in the model. "Substituting these constraints into the distance function is equivalent to normalising by one of the outputs" (O'Donnell and Coelli, 2005; 499). If output $\mathrm{M}$ is chosen to normalise, Equation (1) becomes:

$$
\begin{aligned}
& \ln D / q_{M}=a_{0}+\sum_{m=1}^{M-1} a_{m} \ln q_{m}^{*}+0.5 \sum_{m=1}^{M-1} \sum_{n=1}^{M-1} a_{m n} \ln q_{m}^{*} \ln q_{n}^{*}+\sum_{p=1}^{P} b_{p} \ln x_{p}+ \\
& 0.5 \sum_{p=1}^{P} \sum_{j=1}^{P} b_{p j} \ln x_{p} \ln x_{j}+\sum_{p=1}^{P} \sum_{m=1}^{M-1} g_{p m} \ln x_{p} \ln q_{m}^{*},
\end{aligned}
$$

where $q_{m}^{*}=\mathrm{q}_{\mathrm{m}} / \mathrm{q}_{\mathrm{M}}$. Equation (4) can be written in more compact form as

$$
\ln \left(D / q_{M}\right)=T L\left(x, q / q_{M}, \beta\right)
$$

or

$$
\ln (D)-\ln \left(q_{M}\right)=T L\left(x, q / q_{M}, \beta\right)
$$

where TL (.) represents to the translog function and $\beta$ is the vectors of $a, b$ and $g$ parameters.

Rewriting the equation by substituting $-\ln (D)=-u$ as a one sided error term, captures the effects of inefficiency, we obtain

$$
-\ln q_{M}=T L\left(x, q / q_{M}, \beta\right)-u
$$

A symmetric error term, $v$, can be added in this model to address the effects of data noise. Then the translog model is

$$
-\ln q_{M}=T L\left(x, q / q_{M}, \beta\right)-u+v
$$

The parameters of this model can be estimated using maximum likelihood, assuming that ' $u$ ' is a non-positive random variable independently distributed as truncations at zero of $N\left(0, \sigma_{u}^{2}\right)$ and ' $\mathrm{v}$ ' is an independently and identically distributed random variable which is $N\left(0, \sigma_{v}^{2}\right)$. Equation (8) can equivalently be specified as

$$
\ln q_{M}=T L\left(x, q / q_{M}, \beta\right)-u+v
$$

This translog stochastic distance function is in a normal stochastic frontier form with a two-part error term. As in the ordinary stochastic frontier model, the ' $u$ ' in this model is the deviation from the frontier and ' $V$ ' is a random error. The translog distance can be written as: 


$$
\ln \left(q_{M}^{*}\right)=T L\left(x, q / q_{M}, \beta\right)+v
$$

Equation (9) may be rewritten using equation (10)

$$
\ln q_{M}=\ln q_{M}^{*}-u
$$

or

$$
\ln \left(\frac{q_{M}}{q_{M}^{*}}\right)=(-u)
$$

This illustrates that the technical efficiency (TE) of a farm is the ratio of its mean production to the corresponding mean production if the farm utilised its levels of inputs most efficiently (Battese and Coelli, 1988), i.e.:

$$
T E=\frac{q_{M}}{q_{M}^{*}}=\exp (-u)
$$

This takes values between 0 and 1 , with $T E=1$ indicating that the farm is fully efficient. To sum up, the difference between $q_{M}$ and $q_{M}^{*}$ is embedded in $\mathrm{u}$. If $\mathrm{u}=0$, then $q_{M}$ equals to $q_{M}^{*}$ implying that the production unit lies on the frontier. In this condition, the farm is technically efficient. If $u>0$, the level of the farm's production lies somewhere below the frontier, implying that the farm is technically inefficient.

The technical inefficiency distribution parameter, $u$, can be a function of various operational and farm-specific variables hypothesised as follows

$$
u_{i}=\delta_{0}+\sum_{p=1}^{8} \delta_{p} z_{p i}+w_{i}
$$

where $z_{i}$ is a $1 \times p$ vector of various farm specific variables which may influence efficiency of a farm, $\delta$ is a set of parameters to be estimated and $w_{i}$ 's are the random variables defined by the truncation of the normal distribution with mean 0 and variance $\sigma_{u}{ }^{2}$, such that the point of truncation is $-z_{i} \delta$. i.e., $w_{i} \geq-z_{i} \delta$. These assumptions are consistent with $u_{i}$ being a nonnegative truncation of the $\mathrm{N}\left(z_{i} \delta, \sigma_{u}{ }^{2}\right)$ distribution (Battese and Coelli, 1995). Equations 10 and 14 are simultaneously estimated by maximum likelihood approach running Frontier 4.1 (Coelli, 1996). 


\section{Results and Discussion}

Two hypotheses have been tested with regard to the model specification. The first is a technical inefficiency test which rejects the null hypothesis of no inefficiency effects. The test implies that inefficiency exists in the production system and that specification of the SDF model is justified. The second hypothesis tested is the choice of the functional form, Cobb-Douglas vs. translog. The null hypothesis that the model is Cobb-Douglas is imposed as $a_{m n}=b_{p j}=g_{p m}=0$ in equation 4 . The null hypothesis is rejected, implying that the translog frontier is preferred.

In the stochastic regression results the parameters, $\sigma^{2}=\sigma_{v}^{2}+\sigma_{u}^{2}$ and $\mathrm{Y}=\sigma_{u}^{2} / \sigma^{2}$, represent the variances of the random variables $v_{i}$ and $u_{i}$. The $y$ parameter is estimated to be 0.96 with standard error 0.014 , and is statistically significant. It indicates that $96 \%$ of the variation in the composite error term is due to the inefficiency component. This implies that the random component of the inefficiency effects contributes significantly to agricultural production analysis.

In the output translog distance function, the partial derivative of the output with respect to the $\mathrm{m}^{\text {th }}$ output provides the ratio of the shadow prices of $\mathrm{q}_{\mathrm{M}}$ and $\mathrm{q}_{\mathrm{m}}$. It reflects the slope of the production possibility curve or the marginal rate of transformation between $\mathrm{q}_{\mathrm{M}}$ and $\mathrm{q}_{\mathrm{m}}$. Each of the first order output elasticities with respect to input provide the specific productive contribution to total output. Such elasticities represent the returns to or output contributions from $X_{k}$ changes, similar to output elasticities from production functions. The first-order elasticities of the translog distance-function model can also be decomposed into second-order effects to reflect input or output composition changes as scale expands (Paul and Nehring, 2005). The second-order elasticities provide production complementarities or substitutions among the variables. A negative sign on the elasticity implies a substitute, whereas a positive sign reflects a complement.

The one sided error term, $u$, which is the deviation of a particular observation from the estimated frontier, provides the level of technical inefficiency. The inefficiency measures provide the percentages by which production could be increased, or input use reduced, to reach the production frontier.

An output oriented translog distance function can be said to be well behaved if the function is monotonically increasing and concave in input quantities (Kumbhakar, 1994). Monotonicity implies positive elasticities of inputs within the data range. The complete regression results of the output oriented distance function model across the entire sample are reported in Table 2. All input elasticities with respect to output are positive and highly significant; thus, the model demonstrates a well behaved production technology.

The signs of the first order output coefficients are negative and statistically significant. The second order output elasticities have correct (negative) signs, indicating that the transformation curve has a concave shape. The cross (with the exception of $q_{3} \times q_{4}$ ) and squared output terms are significant 
across specifications, and many cross-input terms are also significant. The result thus indicates the possibility of substitution among output variables.

As expected, the estimated first order output elasticities for all conventional (Xs) inputs have correct (positive) signs and all elasticities are statistically significant at the $1 \%$ level. The positive signs of these elasticities indicate that farms can increase output by using more of these inputs. In output oriented translog distance function the production elasticities indicate how overall output changes with the variation in an individual input, keeping other input and output ratios constant, which is similar to output elasticities in production function estimation (Paul and Nehring, 2005). The elasticity of irrigated land (0.2) indicates that a $1 \%$ rise in irrigated land would increase overall output by $0.2 \%$. In other words, it seems possible to increase output by increasing irrigated land and maintaining the existing levels of other inputs. Similarly, other production elasticities imply that increases in these inputs will also increase output.

Irrigated land is found to have the highest elasticity $(0.20)$ followed by labour $(0.18)$, rain-fed land (0.16), capital stock (0.15), and purchased inputs (0.07). The high elasticity of the irrigated land indicates that irrigation is the most important input determining yields in Nepalese agriculture followed by human labour. The elasticity of uplands or rain-fed lands (0.16) suggests that they are no less important if they are utilised properly. In the same way, increases in the amount of capital, purchased inputs can increase total output. The estimated elasticity for other expenditures (0.03) is relatively small but is highly significant.

Most of the cross $q-X$ terms (17 out of 24) are found to be insignificant.The positive sign of the cross product effect indicates that these variables are complementary. This means that if the value of one variable is increased, it also increases the impact of another variable on total output. The results of the model show that the cross products between variables $x_{1}$ and $x_{3}$ and also $x_{2}$ and $x_{6}$ are positive and statistically significant. The cross products between $x_{1}$ and $x_{4} ; x_{3}$ and $x_{4} ;$ and, $x_{3}$ and $x_{6}$ are also positive but not statistically significant. The rest of the cross products are negative and none of them are statistically different from zero. This indicates that none of these variables are substitutes.

The sum of first-order input elasticities measures distance function-based scale economy. The sum measures the percentage change in output if all inputs were changed proportionally. The sum of the first order input elasticities in this model is equal to 0.78 , i. e., less than 1 .This illustrates the existence of decreasing returns to scale at the mean. Imposing the restriction that the sum of output elasticities of all inputs be equal to 1, we can test the hypothesis of constant returns to scale. As the absolute value of the computed t-statistic 2.47 is greater than the critical t-value at the $5 \%$ level of significance, we reject the null hypothesis of constant returns to scale. The rejection of the null hypothesis is the indication of decreasing returns to scale prevailing in Nepalese agriculture. This suggests that productivity gains could be achieved by reducing the size of the farm (Gilligan, 1998). 


\section{Technical Efficiency}

As noted, the technical efficiency of the farm is the ratio of its mean production to the corresponding mean production if the farm utilised its levels of inputs efficiently. The technical efficiency for each farm can be defined as $T E=\exp \left(u_{i}\right)$, where exp denotes the exponential operator. The estimated technical efficiency scores range widely from 0.07 to 0.93 , with a mean efficiency score of 0.73 . This indicates that a high degree of technical inefficiency is present relative to the best performing farms. It follows that a large proportion of farms operate far from the efficient frontier, implying a substantial scope for improving productivity.

The estimated average efficiency score 0.73 indicates that typical Nepalese farms can increase agricultural production by $27 \%$ adopting the technology and the techniques used by the "best practice" farms. Alternatively, on average, there is the potential to achieve the existing level of output by reducing $27 \%$ of their inputs. The frequency distribution of the estimated technical efficiency scores is reported in Table 3 by farm size classification. The last two columns of Table 3 show the overall (national) frequency distribution. Only $1.32 \%$ of farms had an efficiency index of more than $90 \%$, and $16.49 \%$ of farms were operating in the less than $60 \%$ technical efficiency range. The highest relative frequency of the technical efficiency index is found in the $81-90 \%$ range, followed by $71-80 \%$ and $61-70 \%$ range.

Relative land pressure may be the most important factor in explaining differences in technical efficiency between farm sizes. The average technical efficiency is highest in medium size farms $(77 \%)$, followed by large $(75 \%)$ and small $(72 \%)$. This implies that on average, medium size farms are more efficient than large and small ones. This result cannot be far away from the general expectation. Presumably the observed high efficiency of medium farms is due to farmers having agriculture as their main occupation and allocating their resources more effectively, leading to higher farming intensity.

As Table 3 shows the frequency of farms operating in the less than $50 \%$ range of technical efficiency was $10.41 \%, 10.26 \%$, and $15.32 \%$ in small, medium, and large size farm respectively. This result further confirms the high percentage of less efficient farm in the large farm size group. The mean technical efficiency of $73 \%$ is consistent with other studies using cross section data (Squires and Tabor, 1991; Rawlins, 1985; Taylor and Shonkwiler, 1986). It is also similar to the average efficiency score calculated by Bravo-Ureta and Pinheiro (1993). They found the average efficiency score to be $70 \%$, derived from 30 studies conducted by various authors in developing countries using the stochastic frontier and cross section data.

The difference in the average technical efficiencies in different farm sizes was tested using ANOVA with a one-way classification. The calculated Fratio 25.597 is greater than the critical value of 4.61 , at a $1 \%$ level of significance. This shows strong evidence rejecting the null hypothesis of no 
difference in the average technical efficiency in different farm size groups, so that the average technical efficiency in different farm size groups is significantly different. The average medium size farm is $6.96 \%$ more efficient than an average small farm and $2.13 \%$ more efficient than an average large farm.

Nepalese agriculture is characterised by extreme heterogeneity because of its geographical diversity. Therefore, agro-climatic potential may be one of the important factors explaining differences in agricultural output. Table 4 reports the distribution of efficiency scores by ecological zones. The table shows that the average technical efficiency is similar between the Hill and the Mountain regions, but it is higher in Terai. The higher average efficiency in Terai is as expected. The Mountain and Hill regions are considered to be relatively unproductive because of geographical conditions. The statistical significance test using ANOVA with a one-way classification suggests that the Terai region is more efficient than the Hill and Mountain regions.

The empirical results clearly reveal that the inefficiency scores vary across farm size and ecological zone over time. Next we discuss some specific variables that affect such variations.

The $z_{1}$ to $z_{8}$ variables as defined in Equation (14) are included as potential determinants of technical efficiency. Table 2 also reports the estimates of the technical inefficiency function. The dependent variable is technical inefficiency, not technical efficiency. Thus, a negative sign of the coefficient of an explanatory variable implies a reduction in technical inefficiency or a rise in technical efficiency. Results will be further discussed below.

\section{Nonparametric Data Envelopment Analysis (DEA)}

The purpose of this section is to introduce the DEA model and compare the results with those derived from the SDF model. Though the methodologies to estimate efficiency differ, both methods define technical efficiency as the observed production relative to the corresponding potential, given the quantity of inputs used. The technical efficiency scores estimated from the output-oriented DEA frontiers are therefore comparable with the scores obtained from the SDF. In this section DEA frontiers are estimated using the same output and input variables and the same data set as in the SDF model.

Consider the situation of 2,585 farms, each producing four different types of crops using six different inputs. The ith farm uses $x_{k i}$ units of the $k_{t h}$ input in the production of $y_{r i}$ units of the $r$ th crop. A separate linear programming problem is solved for each of the 2,585 farms in the sample. The outputbased technical efficiency for the ith farm can be obtained by solving the following LP problem:

$$
\underset{\phi_{i}, \lambda_{j}}{\operatorname{Maximise}} \phi_{i}
$$

subject to 


$$
\begin{aligned}
& \phi_{i} y_{r i}-\sum_{j=1}^{2585} \lambda_{j} y_{r j} \leq 0 \quad \mathrm{r}=1, \ldots, 4 \text { outputs, } \\
& x_{k i}-\sum_{j=1}^{2585} \lambda_{j} x_{k j} \geq 0 \quad \mathrm{k}=1, \ldots, 6 \text { inputs } \\
& \sum_{j=1}^{2585} \lambda_{j}=1 \text { (variable returns to scale) } \\
& \lambda_{\mathrm{j}} \geq 0 \mathrm{j}=1, \ldots, 2585 \text { farms, }
\end{aligned}
$$

where $\phi_{\mathrm{i}}$ is the proportional increase in outputs possible and $\lambda_{\mathrm{j}}$ the weight or intensity variable used to derive all possible linear combinations of sample observations. When the value of $\phi_{i}$ in Equation (15) is $1, \lambda_{i}=1$, and $\lambda_{j}=0$ for $\mathrm{j} \neq \mathrm{i}$, the ith farm lies on the frontier and is technically efficient. For the inefficient units, $\phi_{i}>1, \lambda_{i}=0$, and $\lambda_{j} \neq 0$ for $\mathrm{j} \neq \mathrm{i}$. The output based technical efficiency index of the ith farm $\left(T E_{i}\right)$ can be computed as follows:

$$
T E_{i}=\frac{1}{\phi_{i}}
$$

Table 5 presents the results of the empirical estimates of the DEA model. The table shows frequency distribution and summary statistics for the technical efficiency scores in terms of variable returns to scale (VRS), constant returns to scale (CRS) and scale efficiency (SE).The estimated mean technical efficiencies for the sample households for the VRS and CRS DEA frontier are 0.48 and 0.47 respectively. The DEA results also verify that there is substantial productive inefficiency in Nepalese agriculture. Out of 2,585 households, 329 households are fully efficient under the VRS model. However, in terms of the CRS model, only 244 households are fully efficient. The individual efficiency measures derived under the VRS DEA model are equal to or greater than those obtained from the CRS DEA model.

\section{Comparison of TE Scores Derived from SDF and DEA}

Many of studies have compared the technical efficiency results derived from SFA and DEA methods in agriculture (Ferrier and Lovell, 1990; Kalaitzandonakes and Dunn, 1995; Drake and Weyman-Jones, 1996); Sharma et al., 1997; 1999). These findings generally show that while the efficiency scores produced from each approach differ quantitatively, the ordinal efficiency ranking of farms obtained from the two approaches appear similar. Table 5 compares the technical efficiencies derived from SDF and DEA.

Table 5 shows that technical efficiency scores estimated using the two methods vary greatly. The mean technical efficiencies estimated from the DEA models are lower than those estimated from the stochastic frontier. As can be seen, a majority of farm households have efficiency of more than $70 \%$ in terms of SDF but the corresponding figure is very low in the DEA 
results. These results are not surprising because the DEA approach attributes any deviation of the data points from the frontier to inefficiency, whereas the SDF also accounts for a random error component.

As compared to SDF measures, the DEA efficiency measures have a considerably higher variability. The variability of the DEA efficiency measure ranges from a minimum of 0.02 to a maximum of 1 whereas in SFA it ranges from 0.07 to 0.93 . To examine the efficiency rankings between the two approaches, correlation coefficients between the technical efficiency rankings from the SDF and both CRS and VRS scale models of the DEA are computed and reported in Table 6 . The statistical significance test confirms that all the correlation coefficients are positive and significant.

\section{Factors Determining Inefficiency}

There are essentially two ways for estimating the farm specific attributes in explaining inefficiencies. The first is to include farm specific attributes in the efficiency model directly as has been done in the SDF model above. The other approach is to use a second stage regression model as applied in a number of studies including Kalirajan (1991), Sharma, Leung and Zaleski (1999), and Shafiq and Rehman (2000). The second stage regression model is now used to determine the farm specific attributes in explaining efficiency in Nepalese agriculture. The empirical model assumed is as follows:

$$
y^{*}=Z \beta+e
$$

where $y^{*}$ is a DEA efficiency index used as a dependent variable, $z$ is the vector of independent variables related to farm specific attributes, $\beta$ is the unknown parameter vector associated with the farm specific attributes, and $e$ is an independently and normally distributed error term with zero mean and constant variance, $\sigma^{2}$.

As defined earlier in the case of the stochastic model, all $z_{1}-z_{8}$ variables are potential determinants of technical efficiency. Estimated parameters of Equation (18), which are estimated by Tobit regression procedures available in LIMDEP 8.0 (Green, 2002), are reported in Table 7. The response variable in this model is technical efficiency (as opposed to technical inefficiency in the case of SDF model). The signs of the parameters are therefore opposite of the technical inefficiency model above. Thus, the signs are simply changed to make the results of both models comparable.

Table 7 shows that the Tobit regression results are consistent with the SFA model. By and large, the same signs and relative values are found in both model estimations and hence have the same effects on technical efficiency (or inefficiency) of all regressors. With the exception of distance to road, the signs related to all other inefficiency (or efficiency) determinants are as expected. In both cases, owned land has a significantly positive effect on efficiency (or negative effect on inefficiency). The largest absolute value of 
owned land among the Tobit regression coefficients suggests that ownership of land might be the most important determinant of efficiency. As owned land is the proxy of access to agricultural credit, the positive effect on efficiency indicates that farmers with more owned land have more access to agricultural credit so that they are more efficient.

In both models, the value of land, a proxy for land quality, has a significantly negative effect on inefficiency. The household head's age has a positive effect on efficiency in both models. However, the estimated coefficients are not significant in both models. The variable for extension service reflects the influence of the government extension programme. Both regressions give the same result, namely that the extension dummy variable has positive effects on efficiency but it is not statistically significant in both cases.

Surprisingly, the result indicates that the farther from a road, the more efficient the farm. This effect is not expected but it is significantly different from zero. The underlying reason behind this could be that higher quality (irrigated) farmlands are relatively far away from residential areas and town centres so that access to roads is not available. However, the small value of the coefficient in both models suggests that the impact of this variable is quite limited.

The results of both regression models reveal positive relationships between the level of education of the household head and technical efficiency. This is also statistically significant in the DEA model (although not in the SDF model). It suggests that increasing investment in education may lead to better performance in the agricultural sector. The dummy variables for the Mountain and Hill regions have a negative effect on efficiency. This implies that the Terai (plain) region, taken as the base case, has a positive effect on efficiency.

To sum up, farmers with owned land, more education, higher quality of land, and who live in the Terai region have a higher level of technical efficiency than the farmers not possessing those attributes. We next turn to a discussion of the implications of the results.

\section{Conclusions and Policy Implications}

These results suggest that policy makers in Nepal need to understand that there is a high degree of inefficiency in the agricultural production systems. Results show that the variation in output among agricultural farms is due to differences in technical efficiency. Variations in amounts of production inputs have a significant influence on the level of production and efficiency across farm households. Results confirm that the level of inefficiency is also related to farm specific attributes. Owned land is the major determinant of inefficiency followed by land quality (value of land) and education.

The results demonstrate that the level of technical efficiency among agricultural households differs significantly across size groups and across agro-ecological zones. Medium size farms achieve the highest technical 
efficiency in the Nepalese context. Decreasing returns to scale also suggest that productivity gains can be achieved by reducing the size of larger farms.

All this suggests that there is a high prospect of improving technical efficiency and thereby household welfare. Increasing household welfare is an effective way of alleviating poverty. Based on the findings, the following policy implications can be derived with regard to increasing efficiency so as to reduce poverty and promote equity.

In view of the limited arable land and other resources, satisfying the increased demand for food through domestic production must come through improvements in productivity, from technological progress or increases in technical efficiency at the farm level. Technical progress relates to the development and adoption of modern technologies, whereas technical efficiency refers to the farmer's ability to achieve maximum output from a given set of inputs by using available productive technology efficiently. Given the existing production technology in Nepal, there is limited prospect of technical progress. In this context, the policy makers need to understand that an increase in technical efficiency is relatively cost effective and therefore government policies should be directed towards this.

This study shows that given the present state of agricultural technology, farms have a potential for enhancing productivity by increased use of inputs. Irrigation is identified as the main factor for determining yields in agriculture. Therefore, government policy should give a high priority to increasing irrigation facilities. In the same way, government policy should facilitate the supply of and access to required capital, high quality seeds, fertilisers and other inputs for farmers.

Access to agricultural credits, the quality of land and education are recognised as the most influential determinants of efficiency. These are also the shifting factors of the production frontier. Government policies should target increased access to credit for farmers through ownership of land along with enhancement of land quality and increases in the level of education, training and knowledge of farmers. These types of policies and practices could contribute to increased technical efficiency.

The findings reveal that the medium sized farm (i.e., between one and two hectares) is more efficient than large and small sized farms. This suggests maintaining medium farm size would be beneficial. Policies targeted at creating medium sized farms by breaking up large farms and the merger of small farms might have beneficial effects on efficiency, although this issue may need to be studied further. Access to land by the poor through redistributive land reform can increase productivity and promote efficiency.

The existence of a high degree of technical inefficiency also suggests that farmers' resource allocation decisions differ widely among individual farmers. Farmers' interactions with each other should have some beneficial effect towards catching up on new technology. Producers' organisations can also 
improve efficiency in the delivery of government support services and empower them to get involved in many activities.

The analysis clearly demonstrates that technical efficiency varies significantly across farm-size groups and ecological zones. The effectiveness of new policies designed to increase efficiency and productivity may depend largely on the extent to which such differences are recognised. Efficiency improvement policies should be flexible enough to accommodate these realities. For instance, younger and older household managers, educated and uneducated, with and without capital, with irrigated land and rain-fed land, might comprise sub groups with small, medium and large farms located in the Terai, Hill and Mountain ecological zones. Therefore, policies targeting separate groups, rather than 'one size fits all', will be an effective approach to improve efficiency and productivity. In the same way, recognising farmers who are inefficient in using some resources (such as fertiliser, seeds and labour) would be useful in treating them separately for intervention purposes.

The findings suggest that government efforts through agriculture extension programmes have failed to have a significant effect on technical efficiency. Government policies should facilitate the private sector to come forward and assist in diffusing modern technologies through extension and training, so that farmers can apply available agricultural technology more efficiently.

Among the three geographical regions, the observed average inefficiency is higher in the Hill and Mountain regions. Government policies should be targeted to increasing TE in these areas by taking into account the varying circumstances that can be observed.

\section{Acknowledgements}

The authors are grateful to two referees for very helpful comments. 


\section{References}

Battese, G. E. and Coelli, T. J. (1988) Prediction of firm-level technical efficiencies with a generalised frontier production function and panel data, Journal of Econometrics, 38, 387-399.

Battese, G. E. and Coelli, T. J. (1995) A model for technical inefficiency effects in a stochastic frontier production function and panel data, Empirical Economics, 20, 325-332.

Binswanger, H. P., Deininger, K. and Feder, G. (1995) Power, distortions, revolt, and reform in agricultural land relations. In: Behrman, J. and Srinavasan, T. N. (eds.), Hand Book of Development Economics, Vol. III. Elsevier Science Publisher, Amsterdam.

Bravo-Ureta, B. E. and Pinheiro, A. E. (1993) Efficiency analysis of developing country agriculture: a review of the frontier function literature, Agriculture and Resource Economics Review, 22, 88-101.

Central Bureau of Statistics (CBS) (2004) Nepal Living Standards Survey 2003/04 Statistical Report (in two Volumes), CBS, Kathmandu.

Coelli, T. (1996) A Guide to FRONTIER Version 4.1: A Computer Program for Stochastic Frontier Production and Cost Function Estimation, CEPA Working Paper, 07/96. Department of Econometrics, University of New England, Armidale, Australia.

Coelli, T. J. (1995) Recent development in frontier modelling and efficiency measurement, Australian Journal of Agricultural Economics, 39, 219245.

Coelli, T. J. and Perelman, S. (1996) Efficiency measurement, multi-output technologies and distance functions: with application to European railways. CREPP Working Paper 96/05, University of Liege.

Coelli, T. J. and Perelman, S. (2000) Technical efficiency of European railways: a distance function approach, Applied Economics, 32, 196776.

Coelli, T. J., Rao, D. S. P., O'Donnell, C. J. and Battese, G. E. (2005) An Introduction to Efficiency and Productivity Analysis, Springer, New York.

Drake, L. and Weyman-Jones, T. G. (1996) Productive and allocative inefficiencies in UK building societies: a comparison of non-parametric and stochastic frontiers techniques, The Manchester Business School, 64, 22-37.

Ferrier, G. D. and Lovell, C. A. K. (1990) Measuring cost efficiency in banking: econometric and linear programming evidence, Journal of Econometrics, 46, 229-245.

Gilligan D. O. (1998) Farm Size, Productivity, and Economic Efficiency: Accounting for Differences in Efficiency of Farms by Size in Honduras, Paper Presented at AAEA.

Greene, W. H. (2002) LIMDEP Version 8.0: User's Manual and Reference Guide, Econometric Software Inc. New York.

Irz, X. and Thirtle, C. (2005) Dual technological development in Botswana agriculture: a stochastic input distance function approach, Journal of Agricultural Economics, 55, 455-478.

Kalaitzandonakes, N. G., and Dunn, E. G. (1995) Technical efficiency, managerial ability and farmer education in Guatemalan corn production: a latent variable analysis, Agricultural and Resource Economics Review, 24, 36-46. 
Kalirajan, K. P. (1991) The importance of efficient use in the adoption of technology: a macro panel data analysis, Journal of Production Analysis, 2, 113-126.

Kumbhakar, S. C. (1994) Efficiency estimation in a profit maximising model using flexible production function, Agricultural Economics, 10, 143-152.

Lovell, C. A. K., Richardson, S. Travers, P. and Wood, L. L. (1994) Resources and functionings: a new view of inequality in Australia, In: Eichhorn, W. (ed.), Models and Measurement off Welfare and Inequality, Springer-Verlag Press, Berlin.

National Planning Commission (NPC) (1998) The Ninth Plan, NPC, Kathmandu.

O'Donnell, C. J. And Coelli, T. J. (2005) A bayesian approach to imposing curvature on distance Functions, Journal of Econometrics, 126, 493523.

Pascoe, S., Koundouri, P. and Bjørndal, T. (2007) Estimating targeting ability in multi-species fisheries: a primal multi-output distance function approach, Land Economics, 83, 382-397.

Paul, C. J. M. and Nehring, R. (2005) Product diversification, production systems, and economic performance in US agricultural production, Journal of Econometrics, 126, 525-548.

Rawlins, G. (1985) Measuring the impact of I. R. D. P.Il upon the technical efficiency level of Jamaican peasant farmers, Social and Economic Studies, 34, 71-96.

Shafiq, M. and Rehman, T. (2000) The extent of resource use inefficiencies in cotton production in Pakistan's Punjab: an application of data envelopment analysis, Agricultural Economics, 22, 321-330.

Sharma, K. R., Leung, P. and Zaleski, H. M. (1997) Production efficiencies of the swine industry in Hawaii: stochastic frontier vs. data envelopment analysis, Journal of Productivity Analysis, 8, 447-459.

Sharma, K. R., Leung, P. and Zaleski, H. M. (1999) Technical, allocative and economic efficiencies in swine production in Hawaii: a comparison of parametric and nonparametric approaches, Agricultural Economics, 20, 23-35.

Shephard, R. W. (1970) Theory of Cost and Production Functions, Princeton University Press, New York.

Squires, D. and Taber, S. (1991) Technical efficiency and future production gains in Indonesian agriculture, Journal of Development Economics, 29, 258-270.

Taylor, T. G. and Shonkwiler, J. S. (1986) Alternative stochastic specifications of the frontier production function in the analysis of agricultural credit programmes and technical efficiency, Journal of Development Economics, 21, 146-160.

World Bank (WB) (2006) Nepal Resilience amid Conflict: An Assessment of Poverty in Nepal, 1995-96 and 2003-04, World Bank, Washington DC. 
Table 1: Descriptive Statistics of Variables

\begin{tabular}{|l|l|r|r|r|r|}
\hline Variables & Unit & Mean & Std Dev & Minimum & Maximum \\
\hline Value of Cereal Crops $\left(q_{1}\right)$ & Rs & 17532.2 & 20520.3 & 0 & 499728 \\
\hline Value of Pulses $\left(q_{2}\right)$ & Rs & 3503.08 & 8116.14 & 0 & 199026.3 \\
\hline Value of Cash Crops $\left(q_{3}\right)$ & Rs & 5071.42 & 14373.4 & 0 & 350429.8 \\
\hline Value of Others Crops $\left(q_{4}\right)$ & Rs & 12642.6 & 47084.6 & 0 & 1312800 \\
\hline Labour $\left(X_{1}\right)$ & Hours & 7399.22 & 3769.42 & 614 & 50053.01 \\
\hline Irrigated Land $\left(X_{2}\right)$ & Hectares & 0.44 & 0.81 & 0 & 13 \\
\hline Rain-fed Land $\left(X_{3}\right)$ & Hectares & 0.44 & 0.64 & 0 & 8.8 \\
\hline Value of Capital Stock $\left(X_{4}\right)$ & Rs & 5077.1 & 8242.52 & 0 & 148040 \\
\hline Cost of Purchased Inputs $\left(X_{5}\right)$ & Rs & 1662.45 & 3558.66 & 0 & 92800 \\
\hline Other Costs $\left(X_{6}\right)$ & Rs & 1920.44 & 4951.34 & 0 & 109200 \\
\hline Owned Land $\left(Z_{1}\right)$ & Hectares & 0.76 & 0.96 & 0.01 & 18.62 \\
\hline Value of Land Per Hec. $\left(Z_{2}\right)$ & Rs & 1041025 & 2864097 & 10811.5 & 44941927 \\
\hline Age of Family Head $\left(Z_{4}\right)$ & Years & 46.02 & 13.97 & 16 & 91 \\
\hline H.H. Education Level $\left(Z_{5}\right)$ & Years & 3.46 & 3.72 & 1 & 17 \\
\hline Access to Road $\left(Z_{6}\right)$ & Hours & 7.42 & 14.33 & 0 & 120 \\
\hline Source: NLSS dataset & & & & \\
\hline
\end{tabular}

Source: NLSS dataset 
Table

\section{\begin{tabular}{|l} 
Variables \\
\hline Constant
\end{tabular}}

Cereal Crops (q12)

Pulses (q21)

Cash Crops (q31)

Other Crops (q41)

DO1

DO2

DO3

DO4

Cereal×Pulses (nm12)

Cereal $\times$ Cash (nm13)

Cereal $\times$ Other (nm14)

Pulses $\times$ Cash (mn23)

Pulses $\times$ Other (mn24)

Cash $\times$ Other (mn34)

Cereal $\times$ Cereal $(\mathrm{nm} 11)$

\begin{tabular}{|ll|}
\hline Pulses $\times$ Pulses $(\mathrm{mn} 22)$ & -0.008 \\
\hline
\end{tabular}

Cash $\times$ Cash (mn33)

Other $\times$ Other (mn44)

Labour (x1)

Irrigated Land (x2)

Rainfed Land ( $x 3$ )

Capital Stock ( $x 4$ )

Purchased Inputs $(x 5)$

Other Costs $(x 6)$

$\mathrm{D}_{1} 1$

$\mathrm{D}_{2} 2$

D)3

D,4

$\mathrm{D}, 5$

$\mathrm{x} 1 \times 2$

$\mathrm{x} 1 \mathrm{x3}$

$\mathrm{x} 1 \times 4$

$\mathrm{x} 1 \mathrm{x} 5$

$x 1 \times 6$

$x 2 \times 3$

$x 2 \times 4$

$x 2 \times 5$

$x 2 \times 6$

$x 3 \times 4$

$\times 3 \times 5$

$\begin{array}{r}\times 3 \times 6 \\ \hline x \times 5 \\ \hline\end{array}$

$\mathrm{x} 4 \mathrm{x} 5$

$\times 4 \times 6$
Coefficient $\quad$ St. Err.

1.001

$-0.561$

$-0.121$

$-0.182$

$-0.136$

$-4.403$

$-0.788$

$-1.437$

$-1.244$

0.009

$-0.005$

$-0.002$

0.003

$-0.004$

$<.001$

$-0.002$

0.001

0.006

0.177

0.202

0.156

0.148

0.072

0.029

$-0.591$

$-0.274$

$-0.082$

$-0.401$

\begin{tabular}{l|l}
0.201 \\
\hline
\end{tabular}

0.173

$-0.002$

$-0.008$

0.162

0.021

$-0.035$

0.02

0.02

0.012

\begin{tabular}{l|l}
\hline-0.014 & 0.008 \\
\hline
\end{tabular}

$-0.015$

0.008

0.028

$-0.008$

0.009

0.006

$-0.002$

0.008

$<.001$

0.004

0.005

$-0.006$

0.003

$<.001$

$-0.004$

$-0.002$
0.003

0.002

0.002

\begin{tabular}{|c|c|}
\hline t-ratio \\
\hline 32.131 \\
\hline-51.471 \\
\hline-13.465 \\
\hline-19.396 \\
\hline
\end{tabular}

\section{RESULTS (FRONTIER 4.1)}

\begin{tabular}{|l|c|c|c|}
\hline Variables & Coefficient & St. Err. & t-ratio \\
\hline x11 & 0.063 & 0.057 & 1.114 \\
\hline x22 & 0.036 & 0.015 & 2.465 \\
\hline x33 & 0.055 & 0.013 & 4.223 \\
\hline x44 & 0.035 & 0.008 & 4.493 \\
\hline x55 & 0.06 & 0.009 & 6.985 \\
\hline x66 & 0.005 & 0.007 & 0.658 \\
\hline & & & \\
\hline x1q1 & -0.029 & 0.009 & -3.235 \\
\hline x2q1 & 0.016 & 0.004 & 3.739 \\
\hline x3q1 & 0.001 & 0.004 & 0.217 \\
\hline x4q1 & -0.007 & 0.003 & -2.842 \\
\hline x5q1 & $<.001$ & 0.002 & 0.242 \\
\hline x6q1 & -0.001 & 0.002 & -0.662 \\
\hline & & & \\
\hline x1q2 & 0.012 & 0.009 & 1.325 \\
\hline x2q2 & -0.012 & 0.004 & -2.903 \\
\hline x3q2 & -0.003 & 0.004 & -0.699 \\
\hline x4q2 & -0.001 & 0.002 & -0.576 \\
\hline x5q2 & -0.001 & 0.001 & -0.684 \\
\hline x6q2 & 0.002 & 0.002 & 1.41 \\
\hline x1q3 & 0.007 & 0.007 & 0.898 \\
\hline x2q3 & 0.002 & 0.003 & 0.542 \\
\hline x3q3 & 0.002 & 0.003 & 0.543 \\
\hline x4q3 & 0.004 & 0.002 & 2.06 \\
\hline x5q3 & 0.001 & 0.001 & 1.09 \\
\hline x6q3 & -0.003 & 0.001 & -1.892 \\
\hline x1q4 & 0.01 & 0.005 & 1.892 \\
\hline x2q4 & -0.006 & 0.003 & -2.167 \\
\hline x3q4 & $<.001$ & 0.002 & 0.014 \\
\hline x4q4 & 0.004 & 0.002 & 2.502 \\
\hline x5q4 & -0.001 & 0.001 & -0.811 \\
\hline x6q4 & 0.002 & 0.001 & 1.623 \\
\hline & & & \\
\hline Constant (Z0) & -1.07 & 0.71 & -1.51 \\
\hline Owned Land (Z1) & -0.6 & 0.21 & -2.92 \\
\hline Value of Land (Z2) & -0.28 & 0.09 & -3.19 \\
\hline Extension Service (Z3.) & -0.98 & 0.6 & -1.63 \\
\hline Age of HH (Z4) & 0.014 & 0.11 & -0.81 \\
\hline Education of HH (Z5) & 0.05 & -0.68 \\
\hline Access to Road (Z6) & 0.04 & -2.45 \\
\hline Mountain Dummy (Z7) & 0.16 & 0.12 & 1.36 \\
\hline Hill Dummy (Z8) & 0.15 & 2.04 \\
\hline sigma-squared & & 67.99 \\
\hline Gamma & & \\
\hline
\end{tabular}


Table 3: Distribution of Technical Efficiency (TE) by Farm Size

\begin{tabular}{|l|r|r|r|r|r|r|r|r|}
\hline TE \% & Small & $\%$ & Medium & $\%$ & Large & $\%$ & All & $\%$ \\
\hline$<10$ & 4 & 0.22 & 0 & 0 & 2 & 0.45 & 6 & 0.19 \\
\hline $11-20$ & 22 & 1.2 & 1 & 0.19 & 1 & 0.45 & 24 & 0.93 \\
\hline $21-30$ & 26 & 1.42 & 6 & 1.14 & 2 & 0.9 & 34 & 1.32 \\
\hline $31-40$ & 51 & 2.78 & 2 & 0.38 & 3 & 1.35 & 56 & 2.17 \\
\hline $41-50$ & 88 & 4.79 & 16 & 3.04 & 13 & 5.86 & 117 & 4.53 \\
\hline $51-60$ & 147 & 8 & 29 & 5.51 & 14 & 6.31 & 190 & 7.35 \\
\hline $61-70$ & 280 & 15.24 & 63 & 11.98 & 31 & 13.96 & 374 & 14.51 \\
\hline $71-80$ & 586 & 31.9 & 152 & 28.9 & 50 & 22.52 & 788 & 30.48 \\
\hline $81-90$ & 617 & 33.64 & 249 & 47.34 & 96 & 43.24 & 962 & 37.21 \\
\hline$>90$ & 15 & 0.82 & 8 & 1.52 & 11 & 4.95 & 34 & 1.32 \\
\hline $\begin{array}{l}\text { Total } \\
\text { Farm }\end{array}$ & 1836 & 100 & 526 & 100 & 223 & 100 & 2585 & 100 \\
\hline Ave. TE & 0.72 & & 0.77 & & 0.75 & & 0.73 & \\
\hline
\end{tabular}


Table 4: Distribution of Technical Efficiency by Ecological Zone

\begin{tabular}{|l|l|l|l|l|l|l|l|l|}
\hline TE (\%) & Mountain & $\%$ & Hill & $\%$ & Terai & $\%$ & All & $\%$ \\
\hline$<10$ & 0 & 0.00 & 3 & 0.24 & 2 & 0.21 & 5 & 0.19 \\
\hline $11-20$ & 3 & 0.82 & 9 & 0.71 & 12 & 1.25 & 24 & 0.93 \\
\hline $21-30$ & 7 & 1.91 & 17 & 1.35 & 10 & 1.04 & 34 & 1.32 \\
\hline $31-40$ & 9 & 2.45 & 24 & 1.90 & 23 & 2.40 & 56 & 2.17 \\
\hline $41-50$ & 19 & 5.18 & 68 & 5.39 & 30 & 3.13 & 117 & 4.53 \\
\hline $51-60$ & 28 & 7.63 & 104 & 8.25 & 58 & 6.06 & 190 & 7.35 \\
\hline $61-70$ & 56 & 15.26 & 179 & 14.20 & 140 & 14.63 & 375 & 14.51 \\
\hline $71-80$ & 108 & 29.43 & 425 & 33.70 & 255 & 26.65 & 788 & 30.48 \\
\hline $81-90$ & 137 & 37.33 & 418 & 33.15 & 407 & 42.53 & 962 & 37.21 \\
\hline$>91$ & 0 & 0.00 & 14 & 1.11 & 20 & 2.09 & 34 & 1.32 \\
\hline Total & 367 & 100 & 1261 & 100 & 957 & 100 & 2585 & 100 \\
\hline Ave. TE & 0.7214 & & 0.7216 & & 0.7419 & & 0.7291 & \\
\hline
\end{tabular}


Table 5: DEA Results Comparing with SDF Results

\begin{tabular}{|l|l|l|l|l|l|l|l|}
\hline \hline TE (\%) & SDF & $\%$ & CRS & $\%$ & VRS & $\%$ & SE \\
\hline $0-10$ & 5 & 0.19 & 64 & 2.48 & 64 & 2.48 & 0 \\
\hline Nov-20 & 24 & 0.93 & 262 & 10.1 & 261 & 10.1 & 0 \\
\hline $21-30$ & 34 & 1.32 & 542 & 21 & 462 & 17.9 & 0 \\
\hline $31-40$ & 56 & 2.17 & 423 & 16.4 & 488 & 18.9 & 0 \\
\hline $41-50$ & 117 & 4.53 & 371 & 14.4 & 351 & 13.6 & 3 \\
\hline $51-60$ & 190 & 7.35 & 265 & 10.3 & 250 & 9.67 & 8 \\
\hline $61-70$ & 375 & 14.5 & 176 & 6.81 & 158 & 6.11 & 14 \\
\hline $71-80$ & 788 & 30.5 & 101 & 3.91 & 101 & 3.91 & 45 \\
\hline $81-90$ & 962 & 37.2 & 77 & 2.98 & 72 & 2.79 & 116 \\
\hline $91-99$ & 34 & 1.32 & 61 & 2.36 & 50 & 1.93 & 396 \\
\hline 1 & 0 & 0 & 243 & 9.4 & 328 & 12.7 & 2003 \\
\hline Total & 2585 & 100 & 2585 & 100 & 2585 & 100 & 2585 \\
\hline Mean TE & 0.73 & & 0.47 & & 0.48 & & 0.98 \\
\hline Minimum & 0.07 & & 0.02 & & 0.02 & & 0.45 \\
\hline Maximum & 0.93 & & 1 & & 1 & & 1 \\
\hline St. Dev. & 0.15 & & 0.26 & & 0.27 & & 0.06 \\
\hline
\end{tabular}


Table 6: Correlation Matrix for TE Rankings

\begin{tabular}{|l|l|l|l|}
\hline \hline & SDF & CRS & VRS \\
\hline SDF & 1 & & \\
\hline CRS & 0.39347 & 1 & \\
\hline VRS & 0.40048 & 0.98386 & 1 \\
\hline
\end{tabular}


Table 7: Estimates of Determinants of Technical Inefficiency (First Stage and Second Stage) Models

\begin{tabular}{|c|c|c|c|c|c|c|}
\hline \multirow[t]{2}{*}{ Variable } & \multicolumn{3}{|c|}{ SDF Model } & \multicolumn{3}{|c|}{ Tobit Model } \\
\hline & Coef. & St. Er. & t-Ratio & Coef. & St. Er. & t_Ratio \\
\hline$Z 0$ & -1.07 & 0.71 & -1.51 & -0.449 & 0.022 & -20.457 \\
\hline Z1 (Owned Land) & -0.6 & 0.21 & -2.92 & -0.014 & 0.006 & -2.395 \\
\hline Z2 (Value of Land) & -0.28 & 0.09 & -3.19 & -0.001 & $<0.001$ & -5.295 \\
\hline Z3 (Extension) & -0.98 & 0.6 & -1.63 & -0.009 & 0.02 & -0.462 \\
\hline Z4 (Age) & -0.09 & 0.11 & -0.81 & $-<0.001$ & $<0.001$ & -1.097 \\
\hline Z5 (Education) & -0.04 & 0.05 & -0.68 & -0.005 & 0.002 & -2.92 \\
\hline Z6 (Road) & -0.09 & 0.04 & -2.45 & -0.002 & $<0.001$ & -5.792 \\
\hline$Z 7$ (Mountain) & 0.16 & 0.12 & 1.36 & 0.064 & 0.019 & 3.41 \\
\hline Z8 (Hill) & 0.15 & 0.08 & 2.04 & 0.064 & 0.012 & 5.354 \\
\hline sigma-squared & 3.276 & 1.073 & 3.052 & & & \\
\hline Gamma & 0.962 & 0.014 & 67.991 & & & \\
\hline Sigma & & & & 0.268 & 0.004 & 71.903 \\
\hline
\end{tabular}

